Portland State University

PDXScholar

\title{
The Effects of Chronic Chemogenetic Stimulation of Nucleus Accumbens on Binge Drinking, the Transcriptome, and Neuronal Morphology
}

Dar'ya Y. Pozhidayeva

Portland State University

Follow this and additional works at: https://pdxscholar.library.pdx.edu/honorstheses Let us know how access to this document benefits you.

\section{Recommended Citation}

Pozhidayeva, Dar'ya Y., "The Effects of Chronic Chemogenetic Stimulation of Nucleus Accumbens on Binge Drinking, the Transcriptome, and Neuronal Morphology" (2019). University Honors Theses. Paper 724.

https://doi.org/10.15760/honors.741

This Thesis is brought to you for free and open access. It has been accepted for inclusion in University Honors Theses by an authorized administrator of PDXScholar. Please contact us if we can make this document more accessible: pdxscholar@pdx.edu. 
The Effects of Chronic Chemogenetic Stimulation of Nucleus Accumbens on Binge Drinking, The Transcriptome, and Neuronal Morphology

\author{
by
}

Dar'ya Pozhidayeva

An undergraduate honors thesis submitted in partial fulfillment of the

\author{
requirements for the degree of \\ Bachelor of Science \\ in \\ University Honors \\ and \\ Biochemistry
}

Thesis Adviser

Angela Ozburn, Ph.D. 


\section{INTRODUCTION}

The prevalence of alcohol abuse is $>26 \%$ in the US population. The socioeconomic burden associated with alcohol is $\$ 249$ billion/year, where $75 \%$ of this cost is related to binge drinking. Binge drinking is a problematic pattern of behavior that often leads to alcohol use disorders (AUD). Binge drinking is defined by the NIAAA as having 4-5 drinks within $2 \mathrm{hrs}$ and/or achieving a blood alcohol level (BAL) $>80 \mathrm{mg} \%$. Limited access ethanol drinking paradigms are used to model binge/intoxication in animal models (however, not all limited access paradigms and animal strains drink to intoxication). In the limited access Drinking in the Dark (DID) paradigm, mice are offered an ethanol solution early into the active period of their circadian cycle and can achieve BALs $>80 \mathrm{mg} \%$, suggesting they drink to intoxication (1). C57BL/6J mice are typically reported as high drinking and can achieve BALs $>80 \mathrm{mg} \%$ in the DID paradigm, however significant inbred strain differences have been observed suggesting there exists a genetic contribution to this phenotype $(2,3)$. The DID assay was used to independently create two lines of mice, HDID-1 and HDID-2, that were selectively bred (from HS/Npt progenitors) for high BALs after DID $(4,5)$. HDID and HS/Npt mice have been extensively characterized; HDID mice represent a unique genetic animal model of risk for drinking to intoxication (6-15). Current FDA approved compounds for AUD treatment, as well as several investigational compounds, have been tested for efficacy in reducing binge-like drinking using the DID paradigm in C57BL/6J and HDID mice, as well as other genotypes (16-21). Together, this work suggests that testing potential therapies in more than strain may represent a more beneficial strategy for clinically translational studies. 
Alcohol abuse leads to long lasting changes in reward- and stress-related neuronal circuitry. A significant point of convergence for this circuitry is the nucleus accumbens (NAc). Koob and Volkow (2010) reviewed decades of clinical and preclinical studies to address the neural circuitry associated with the three stages of the addiction cycle: binge/intoxication, withdrawal/negative affect, and preoccupation/anticipation (22). The NAc is identified as an important region for each of these three stages, further supporting its role as a significant point of convergence in the neurocircuitry of addiction. Lesions of the NAc core reduce limited access alcohol intake in mice and relapse rates in alcohol dependent patients but may cause irreversible cognitive deficits in humans (23-25). Cassataro et al. (2014) reported that inhibiting the NAc core [via clozapine-n-oxide or CNO, and hM4Di, an inhibitory Designer Receptor Exclusively Activated by Designer Drugs (DREADD)], reduced limited access drinking in male C57BL/6J mice (23). There is also extensive evidence that stimulating, or increasing activity in these brain regions reduces alcohol drinking, craving, and relapse (26). To achieve this, clinical studies have applied deep brain stimulation (DBS) to the NAc in humans (27-29). Human studies were carried out in treatment resistant alcoholics, where NAc DBS of the shell relieved symptoms of craving and reduced relapse (27). Knapp et al. (2009) showed that DBS of either the NAc core or shell reduces alcohol drinking in rats (using a continuous access paradigm) (30). Henderson et al. (2010) tested the efficacy of NAc DBS (in rats selectively bred for high alcohol preference; $\mathrm{P}$ rats) to reduce alcohol intake in two paradigms (31). In the first experiment, they found that NAc DBS acutely reduced alcohol drinking in rats with chronic drinking experience (continuous access) and in a second experiment they found 
that NAc DBS reduced relapse-like drinking (drinking after chronic continuous access followed by a period of forced abstinence). NAc DBS has also been shown to effectively reduce craving for morphine, heroin, and cocaine (32-34). Many of these studies report that DBS of either the NAc core or shell (or both) are effective in reducing drug-related behaviors in males. Although DBS of the NAc decreases alcohol drinking and craving, its effects are not lasting (reviewed in (35)).

The promising results of NAc DBS studies led us to test whether DREADDs could be used to alter neuronal activity in the NAc and whether they could alter bingelike drinking. There are two sub-regions of the NAc, the shell (more medial and ventral aspect) and core (more lateral and dorsal aspect). In Purohit et al. (2018), we found that increasing activity (via CNO/hM3Dq) in the entire NAc, or just the NAc core is sufficient to decrease binge drinking in $\mathrm{C} 57 \mathrm{BL} / 6 \mathrm{~J}$ females. Here, we test whether this effect is observed in another high drinking mouse line (HDID-1). DREADDs are mutagenized GPCRs, and since we know GPCRs play an important role in neuroplasticity, we test the hypothesis that chronic stimulation of DREADDs could lead to lasting reductions in binge-like drinking. We hypothesize that this behavioral plasticity can be observed at the molecular level via lasting changes in the transcriptome and in neuronal morphology. Here, we focused on identifying genes and biological pathways that are altered with chronic binge-drinking and ameliorated with chronic CNO treatment. We then pharmacologically targeted these biological pathways to determine whether they reduce binge like drinking. 


\section{METHODS AND MATERIALS}

Experimental Animals: Adult High Drinking in the Dark line 1 (HDID-1) (generously provided by Dr. John Crabbe, Portland, Oregon, USA) mice aged 2-5 months were used for experiments in this study. HDID-1 mice are a genetic model of risk for drinking to intoxication and were selectively bred from a genetically heterogeneous stock, $\mathrm{HS} / \mathrm{Npt}$ $(4,5)$. Mice were bred and maintained in a reversed 12/12-h light/dark cycle, with lights off at 08:30 and lights on at 20:30. Cages were made of polycarbonate $(28 \times 17 \times 11.5$ $\mathrm{cm}$ ) containing about $2.5 \mathrm{~cm}$ of cob bedding. Purina brand food (5LOD, PMI Nutrition International, Brentwood, MO) was suspended in a wire-top, and food and water were available ad libitum. All procedures in this study were performed in accordance with $\mathrm{NIH}$ Guidelines for the Care and Use of Laboratory Animals and were approved by the VA Portland Health Care System's Institutional Animal Care and Use Committee.

Drinking in the Dark (DID): Binge-like drinking of ethanol in mice was assessed using Drinking in the Dark (36). All mice had daily access to $20 \%$ ethanol ( $v / v$, in tap water; Decon Laboratories, Inc., PA, USA) for two hours (offered three hours into lights off).

Drugs: For experiments 1 and 2: 30 minutes prior to DID, mice received IP injections of either vehicle [VEH; $1 \%$ DMSO (Hybri-Max, Sigma Life Sciences) in saline $(0.9 \% \mathrm{NaCl}$; Baxter International, Illinois)], or $1 \mathrm{mg} / \mathrm{kg}$ CNO (1\% DMSO in saline; RTI International, North Carolina, USA). For experiment 3, 60 minutes prior to DID, mice were injected IP with either vehicle (5\% DMSO in Dulbecco's phosphate buffered saline; Gibco, Sigma 
Life Sciences, MO, USA) or 5 or 20 mg/kg LMK 235 (Selleck Chemicals, LLC, TX, USA).

Experiment 1: Female HDID-1 mice (S32.G34) were anesthetized with a mixture of ketamine $(125 \mathrm{mg} / \mathrm{kg})$ and xylazine $(12.5 \mathrm{mg} / \mathrm{kg})$ in saline and received bilateral stereotaxic infusions of $1 \mathrm{uL}$ purified high titer AAV into the NAc [rAAV2-hSyn-eGFP (GFP; n=15), rAAV2-hSyn-HA-hM3D(Gq)-IRES-mCitrine (hM3Dq; n=13), or rAAV2hSyn-HA-hM4D(Gi)-IRES-mCitrine (hM4Di; n=8); (from bregma, in mm: angle 10, AP +1.5, Lat +1.7, DV -4.6 and $-4.0 ; 0.5$ uL delivered at DV -4.6 and 0.5 uL delivered at DV4.0)]. AAV titers were $2-3.5 \times 10^{\wedge} 12 \mathrm{vg}$ and were purchased from the University of North Carolina Viral Vector Core. Mice were individually housed and habituated to novel sipper tubes one week prior to DID. The DID experiment was 6 weeks long. Mice were serially treated with vehicle prior to DID during week 1 to establish baseline drinking, then CNO during weeks 2-5 to measure the effects of chronic treatment, and then mice were treated with vehicle again during week 6 to determine if there were any lasting effects of chronic CNO treatment. The serial treatment is represented in the figures as VEH/CNO/VEH. Ethanol intake was measured as described in Purohit et al. (2018) (36). At the completion of this study, mice were deeply anesthetized and transcardially perfused with $0.01 \mathrm{M}$ PBS and $4 \% \mathrm{w} / \mathrm{V}$ paraformaldehyde (PFA). Brains were extracted, sectioned at $30 \mu \mathrm{m}$ using a freezing stage microtome (Model No. 860, American Optical Corp., Buffalo, New York, USA), and processed for immunofluorescence to verify injection placements. 
Immunohistochemical staining was performed following standard procedures using rabbit anti-GFP or anti-HA primary antibody (anti-GFP: AbCam, Catalog\#ab290, 1:20,000 diultion; anti-HA: Cell Signaling Technologies, Catalog \#3724S, 1:1000 dilution) and goat anti-rabbit Alexa 488 secondary antibody (Thermofisher Scientific, Catalog \#A11088, 1:500 dilution factor). Brain sections were mounted on microscope slides (Fisherbrand, \#12-550-15) using Vectashield Antifade Mounting Medium with DAPI (Vector Laboratories, Burlingame, CA) and observed using an Olympus BX60 fluorescence microscope (Olympus, Center Valley, PA, USA). Animals were excluded if expression was not localized to the NAc (hM4Di $n=2$, GFP $n=3$ ).

Experiment 2: Female HDID-1 mice (S35.G37) were stereotaxically injected with $0.5 \mathrm{ul}$ uL rAAV2/5-CMV-Cre-GFP and 0.5uL rAAV2-hSyn-DIO-hM3Dq-mCherry bilaterally into the NAc (from bregma, in mm: angle $10^{\circ}, \mathrm{AP}+1.34$, Lat +1.5 , DV -4.5 ). $A A V$ titers were $4-8 \times 10^{\wedge} 12 \mathrm{vg}$ and were purchased from the University of North Carolina Viral Vector Core (Cre) and Add Gene (DIO constructs). Mice were individually housed and habituated to novel sipper tubes one week prior to DID. The DID experiment was 6 weeks long (as described for experiment 1); however, there were 2 fluid groups (water or ethanol) and 2 treatment groups (VEH/VEH/VEH or VEH/CNO/VEH). Mice were serially treated with vehicle prior to DID during week 1 to establish baseline drinking, then vehicle or CNO during weeks 2-5 to measure the effects of chronic treatment, and then mice were treated with vehicle again during week 6 to determine whether there were any lasting effects of chronic $\mathrm{CNO}$ treatment. Ethanol intake was measured as described in Purohit et al. (2018). For transcriptomic analysis, mice $(n=11-12 /$ fluid 
type/treatment) were euthanized one day after the last DID session via cervical dislocation and rapid decapitation. Frozen tissue punches were collected from the NAc and processed for RNA Sequencing. For neuronal morphology analysis, female HDID-1 mice (S34.G36; $n=4-5 /$ fluid type/treatment) were deeply anesthetized and transcardially perfused with $0.01 \mathrm{M} \mathrm{PBS}$ and $4 \% w / v$ paraformaldehyde (PFA). Brains were extracted and placed in 4\% PFA for 24 hours at $4^{\circ} \mathrm{C}$ before processing for Golgi-Cox staining (as described in (37)). After 14 days at room temperature and low ambient light, the tissue was transferred into a $30 \% \mathrm{w} / \mathrm{v}$ sucrose solution for $24-72$ hours (low light at $4^{\circ} \mathrm{C}$ ), prior to sectioning and mounting. Brains were sectioned coronally using a Compresstome at $200 \mu \mathrm{m}$ (Model VF 300-0Z Microtome with AutoZero Z technique, Precisionary, Greenville, NC, USA) and mounted on gelatin-coated slides. Slides were prepared according to section 2.3 of Bayram-Weston et al., 2016, and cover-slipped with Permount ${ }^{\mathrm{TM}}$ Mounting Medium (Fisher Scientific Co., Waltham, MA, USA).

Experiment 3: Adult male and female HDID-1 mice (S38.G40, S39.G41, S41.G43) were individually housed and habituated to novel sipper tubes one week prior to DID. Mice were tested 4 days per week (as in (1)). Mice were serially treated with vehicle prior to DID (during weeks 1 or $1 \& 2$ ) to establish baseline drinking, and then 0,5 , or $20 \mathrm{mg} / \mathrm{kg}$ LMK 235 over the next 2 weeks to measure the effects of chronic treatment with this HDAC4/5 inhibitor. Ethanol intake was measured using volumetric tubes in $2 \mathrm{hr}$ intervals on all 4 days (8). 
Microscopy: NAc medium spiny neurons were traced with the software Neurolucida (Version 11, MBF Bioscience, Williston, VT, USA) on a Leica DM500b microscope using a DFC36 FX camera. Data analyzed were complexity (sum of the terminal orders + the number of terminals) ${ }^{\star}$ (total dendritic length/number of dendrites), average dendrite length $(\mu \mathrm{m})$, node and end quantity, total dendritic length $(\mu \mathrm{m})$, sum of the terminal orders (number of sister branches encountered when tracing a dendrite from the tip back to the cell body), dendrite quantity, branch sum (total number of segments between node), sholl analysis intersections, sholl analysis length $(\mu \mathrm{m})$, sholl analysis nodes, sholl analysis ends, and sholl analysis area under the curve. The sholl analysis radii were $10 \mu \mathrm{m}$.

RNA Sequencing and Validation of viral gene transduction: NAc tissue punches were mechanically homogenized in PureZol and the RNA isolated using the Aurum Total RNA Fatty and Fibrous Tissue kit (Bio-Rad Laboratories, Inc., Hercules, CA). RNA (100 ng) was processed to cDNA using the BioRad iScript cDNA synthesis kit (Catalog \#: 1708890; Bio-Rad Laboratories, Inc., Hercules, CA) according to manufacturer's protocol. Quantitative real-time PCR was used to measure expression of mCherry to confirm viral expression of hM3Dq-mCherry in samples. A custom mCherry (FOR: 5'AGCGCGTGATGAACTTCGA -3' REV: 5' CGCAGCTTCACCTTGTAGATGA-3'; 5' 6FAM, 3' lowa Black FQ) primer set and Rps18 (Mouse, FAM, qMmuCEP0053856) probe were used and purchased from Bio-Rad Laboratories, Inc., Hercules, CA. mCherry expression levels (relative to $18 \mathrm{~s}$ ) were verified as detectable and similar for all samples (data not shown). RNA samples were then sent to the Massively Parallel 
Sequencing Shared Resource (MPSSR) at OHSU for quality assessment (via 2100 BioAnalyzer, Agilent Technologies, Palo Alto, CA). The library was prepared using the Illumina TruSeq RNA-Seq Library Protocol and quality checks were performed using a. Sequencing was executed via an Illumina HiSeq 2500 Sequencer (Illumina, San Diego, CA, USA) with poly(A)+ stranded selection and paired-end reads at 50 cycles.

\section{Data analysis and statistics:}

Behavior: For experiments 1 and 2, daily alcohol intake data was averaged for each mouse for each treatment period. Intake data were then analyzed using a repeated measure one-way analysis of variance (ANOVA) was performed to determine effect of treatment period on drinking. For significant results $(p<0.05)$, Post-hoc tests were carried out to compare baseline drinking to $\mathrm{CNO}$ treatment and washout periods. For experiment 3, drinking data for each $2 \mathrm{hr}$ interval was averaged for each period (baseline vs treatment weeks). Data was analyzed using a two way repeated measures ANOVA (dose $\mathrm{x}$ treatment period).

Transcriptomic Analysis: Raw FASTA files generated from sequencing were aligned to the Genome Reference Consortium Mouse Reference 38, based on the Mus musculus strain C57BL/6J (GRCm38; also known as mm10). File quality was assessed using FastQC (38) and alignment was run using STAR: ultrafast universal RNA-seq aligner (39) (version: 2.6.0) where paired-end reads were specified, the maximum number of mismatches per pair was indicated as 3 and maximum number of multiple alignments 
allowed per read was indicated as 1. Count data was generated using HTSeq (version 0.9.1) (40) against the Encode vM4 annotation with paired-end read order specification. After filtering, normalization and differential expression were performed using Bioconductor (version 3.34.9) in R (41). The Limma voom (42) function was utilized to perform empirical Bayes-moderated t-statistics to identify Differentially Expressed Genes (DEGs, $p<0.05)$ between fluid and treatment groups. Mean-variance relationships and observational-level weights were calculated from log2-counts per million (log-CPM). Gene expression overlap was identified using BioVenn (43). Weighted gene co-expression network analysis (WGCNA; version 1.67) was performed using R implementation (44). A signed, hybrid co-expression network was constructed. 24,421 genes met the cut off of 1 CPM. Prior to network construction, $10 \%$ of genes exhibiting the lowest correlation values were removed via SUMCOR as in Tritchler et al., 2009 (45). The co-expression network was constructed via Pearson correlation between all gene pairs and the exponentiation of the resulting absolute value to a power beta $=7$. A consensus network was constructed utilizing samples from all sequenced RNA samples. Modules were detected in each network via hierarchical clustering where average linkage and the WGCNA cuttreeHybrid function was used with the following parameters: cutHeight $=0.998$, minClusterSize $=100$, and deepSplit $=0$. The resulting modules were identified by arbitrarily chosen colors. Total network connectivity (degree) of each gene was calculated via the sum total of all edges in the network, where modular connectivity restricted the edges included to the gene's own module. Pseudo and Riken genes exhibiting abnormally high connectivity were sequestered and removed. Module quality was assessed using the WGCNA modulePreservation 
function. The enrichR algorithm $(46,47)$ was used to identify gene ontology annotation enrichment for biological pathways.

Morphology: As the data was nested, with multiple neurons within a brain (dependent) being compared to multiple neurons from other brains (independent) we used a linear mixed effect analysis (48). We did this using $R$ and the package Ime4 (49) to perform a multilevel analysis. The animal was accounted for as a random effect, due to multiple cells for each animal being examined. We used the fluid type (EtOH vs. $\mathrm{H} 2 \mathrm{O}$ ) and the treatment (CNO vs. Vehicle) as fixed effects, and p-values were obtained by likelihood ratio tests. For all morphometric parameters, we examined the main effect of both variables, as well as their interaction. We then corrected for multiple comparisons using the Benjamini-Hochberg approach (50) to adjust the p-values to the q-values of the False Discovery Rate (FDR). Sholl analyses were analyzed by radius as well as area under the curve (AUC). P-values and q-values less than 0.05 were considered significant, and data is presented as mean \pm standard error of the mean.

\section{RESULTS}

Experiment 1: Chronically increasing Gq signaling in the NAc produces lasting reductions in binge-like drinking 
To identify the effect of manipulating NAc activity (via CNO and hM3Dq- or hM4DiDREADDs) on binge-like drinking, HDID-1 mice were subjected to a limited access Drinking in the Dark (DID) paradigm. The effects of treatment (via serial administration of vehicle, $\mathrm{CNO}$, and vehicle) on ethanol binge-like drinking in mice expressing GFP

(Figure 1A), hM4Di (Figure 1B), and hM3Dq (Figure 1C) is presented as the mean $(+/-$

SEM) ethanol
intake
$(\mathrm{g} / \mathrm{kg} / 2 \mathrm{hr})$
across each
treatment
period. Mice
expressing
GFP or hM4Di
in the NAc did
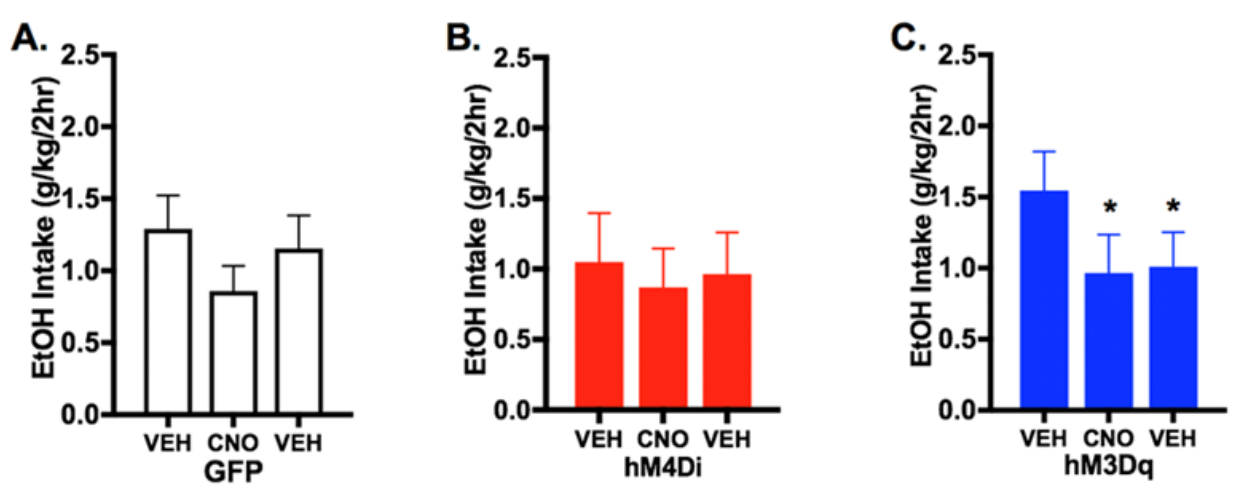

Figure 1. Chronically increasing Gq signaling in the NAc produced lasting reductions in binge-like drinking. Mean (+/- SEM) 2-hour ethanol (EtOH) intake during drinking in the dark (DID) is shown as a function of treatment period for each group as follows: (A) GFP, (B) hM4Di, and (C) hM3Dq. (C) Significant decreases were observed only in hM3Dq during CNO treatment and washout, relative to baseline intake [one way ANOVA - $F(2,35)=4.84, p$ $<0.05$; post-hoc - VEH(baseline) vs CNO, * $p<0.05$; VEH(baseline) vs VEH(washout), * $p$ $<0.05]$. No significant differences in intake over treatment periods were observed for GFP and hM4Di groups.

not exhibit significant changes in ethanol intake during CNO treatment or vehicle washout periods (relative to baseline intake). However, mice expressing hM3Dq in the NAc exhibited a significant reduction in ethanol intake during chronic CNO treatment and during the vehicle washout periods relative to vehicle baseline intake [one way ANOVA - $F(2,35)=4.84, p<0.01$; post-hoc - VEH(baseline) vs CNO, $p<0.05$; VEH(baseline) vs VEH(washout), $p<0.05]$. This suggested that chronically increasing Gq signaling in the NAc produced lasting effects on binge-like drinking behaviors. 


\title{
Experiment 2: Chronically increasing Gq signaling in the NAc produces lasting
}

\author{
reductions in binge-like drinking, the transcriptome, and neruonal morphology.
}

Results from experiment 1 suggested that chronic stimulation using hM3Dq excitatory DREADDs produced a robust and lasting reduction in binge-like drinking in our animal model, thus the

previous study was

replicated using hM3Dq

DREADDs exclusively. Here,

the results of chronic CNO

administration in mice

hM3Dq excitatory DREADDs

in the NAc were similar to

data from experiment 1.

Figure 2A shows ethanol

drinking in response to
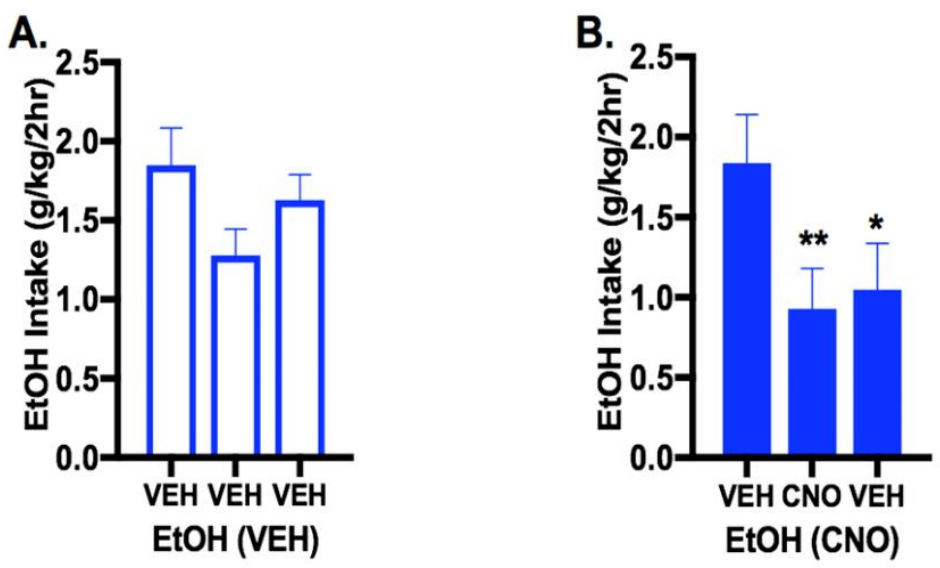

Figure 2. Chronically increasing Gq signaling in the NAc produces lasting reductions in binge-like drinking. Mean (+/- SEM) 2-hour intake during DID weeks is shown as a function of treatment period. (A) No significant decreases in binge-like $\mathrm{EtOH}$ intake were observed in response to chronic treatment with vehicle throughout the duration of the experiment. (B) Robust, significant reductions in binge-like $\mathrm{EtOH}$ intake were observed in response to $\mathrm{CNO}$ treatment and these reductions persisted during the washout period [one way ANOVA - $F(2,35)=10.49, p<0.01$; post-hoc test revealed significant differences for VEH baseline vs CNO $\left.{ }^{* *} p<0.01\right)$ and VEH baseline vs VEH washout $\left.\left({ }^{*} p<0.05\right)\right]$.

chronic treatment with vehicle throughout the duration of the experiment (open bar).

This group experienced no significant changes at any point of the experiment in average ethanol intake $(\mathrm{g} / \mathrm{kg} / 2 \mathrm{hr}$ DID session) relative to baseline intake. 
Conversely, the group treated with $\mathrm{CNO}$ shown in Figure 2B experienced significant and lasting reductions in ethanol intake during CNO treatment [one way ANOVA $F(2,35)=10.49, p<0.01$; Dunnett post-hoc test revealed significant differences for VEH baseline vs CNO $(p<0.01)$ and VEH baseline vs VEH washout $(p<0.05)]$. Replication of this finding provides strong evidence for behavioral plasticty. We next sought to

A.

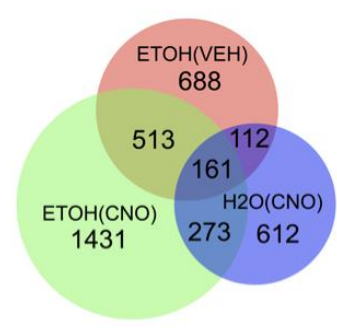

C.
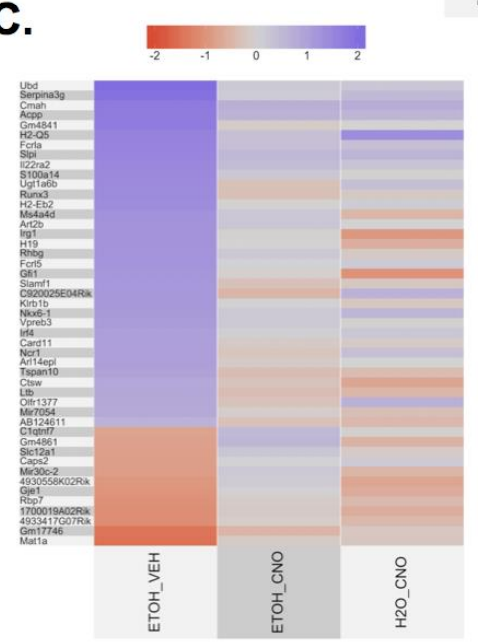

E.

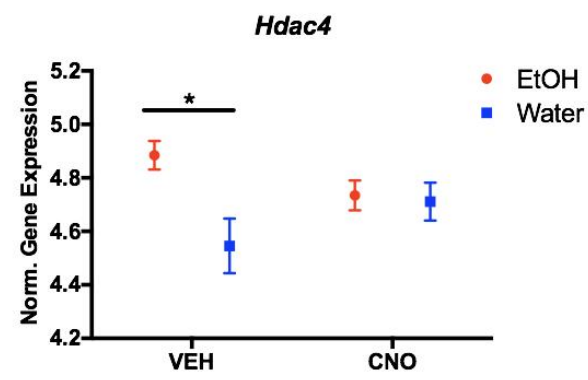

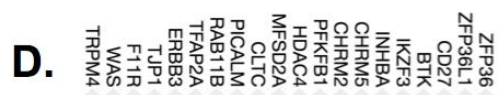

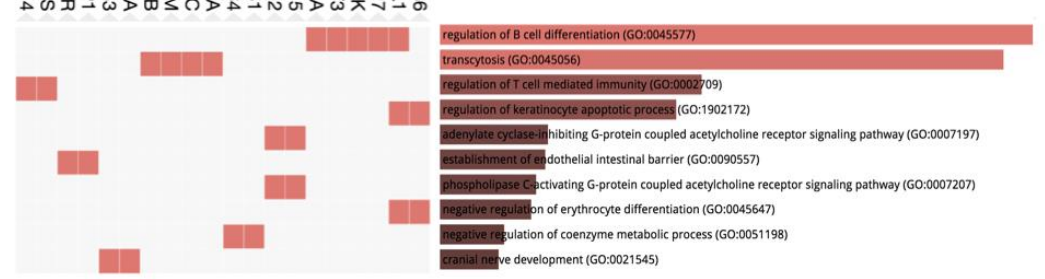

Figure 3. Gene expression changes produced by chronic binge drinking and stimulation of $\mathrm{Gq}$ signaling in the NAc. (A) The venn diagram represents overlapping or unique DEGs $(p<0.05)$ in each group based on pairwise compairson of all groups to H2O(VEH) mice. (B) Gene expression patterns of DEGs associated with binge-like $\mathrm{EtOH}$ drinking identified in $(\mathrm{A})$ across groups are visualized by heatmaps, where blue corresponds to positive expression, red negative and gray minimal to no change in expression. The left panel of $(B)$ represent 688 DEGs associated with $\mathrm{EtOH}(\mathrm{VEH})$, the middle panel represents the 1431 associated with $\mathrm{EtOH}(\mathrm{CNO})$ and the right panel represents the 612 associated with $\mathrm{H} 2 \mathrm{O}(\mathrm{CNO})$. (C) To identify genes changed with chronic binge drinking that were ameliorated with $\mathrm{CNO}$, we highlight the expression patterns in this heatmap for the top 47 DEGs with greatest variability (pairwise Euclidean distance $>1.5$ standard deviations from mean) for the 688 unique to $\mathrm{EtOH}$ (VEH) as compared with other treatment/fluid groups. (D) A clustergram is shown to visualize results from $\mathrm{GO}$ performed on the 688 DEGs identified from $\mathrm{EtOH}(\mathrm{VEH})$ shown in (A). Here enriched terms are shown in each row and input genes are in columns. The cell colors in the matrix indicate if a gene is associated with a term (red) based on its combined z-score and $p$-value. The rank of enriched terms is determined by the combind $p$-value and $z-$ score of each term where the light red indicates high rank and significance and dark red indicates low. (E) Normalized gene expression levels of Hdac4 are shown for each treatment and fluid group. A significant increase in normalized expression was observed between fluid types receiving vehicle treatment [two-way ANOVA: Fluid $x$ Treatment interaction $-F(1,41)=4.45, p<$ 0.05 ; main effect of fluid $-F(1,41)=6.23$, $\mathrm{p}<0.05$; post-hoc test revealed $\mathrm{EtOH}(\mathrm{VEH})$ vs $\mathrm{H} 2 \mathrm{O}$ (VEH), $\mathrm{p}<0.05)$ ].

identify how this plasticity manifested on a transcriptomic and morphological level. 
To identify gene expression changes that change with binge drinking and CNO treatment, differential expression analysis was performed using four groups from experiment 2. These four groups were defined as untreated binge-drinking $(\mathrm{EtOH}(\mathrm{VEH}))$, treated binge-drinking $\mathrm{EtOH}(\mathrm{CNO})$, treated water drinking $(\mathrm{H} 2 \mathrm{O}(\mathrm{CNO}))$ and control water drinking $(\mathrm{H} 2 \mathrm{O}(\mathrm{VEH}))$ animals. Comparisons made between groups involved the pairwise compairson of all groups with the control $\mathrm{H} 2 \mathrm{O}(\mathrm{VEH})$ only. In this way, we identified differentially expressed genes from all groups relative to the control. The lists of differentially expressed genes were then compared for either overlapping or unique genes based on each group.

We identified that there were 1,473 differentially expressed genes $(p<0.05)$ in $\mathrm{EtOH}(\mathrm{VEH})$ relative to control. In $\mathrm{EtOH}(\mathrm{CNO})$ relative to the control, 2,377 differentially expressed genes were observed. We observed 1,157 differentially expressed genes $\mathrm{H} 2 \mathrm{O}(\mathrm{CNO})$ as compared with controls. The overlap in these DEGs is illustrated in Figure 3A. Here, 688 DEGs were uniquely differentially expressed in $\mathrm{EtOH}(\mathrm{VEH})$. In $\mathrm{EtOH}(\mathrm{CNO})$ 1,431 genes were uniquely differentially expressed and in $\mathrm{H} 2 \mathrm{O}(\mathrm{CNO}) 612$ genes were differentially expressed. The overlap for DE was highest between the $\mathrm{EtOH}$ (VEH) and $\mathrm{EtOH}(\mathrm{CNO})(\mathrm{N}=513)$ and lowest between $\mathrm{EtOH}(\mathrm{VEH})$ and $\mathrm{H} 2 \mathrm{O}(\mathrm{CNO})$ $(\mathrm{N}=112)$. Expression patterns for the unique DE genes identified for $\mathrm{EtOH}(\mathrm{VEH}), \mathrm{EtOH}$ (CNO) and $\mathrm{H} 2 \mathrm{O}(\mathrm{CNO})$ are shown in Figure 3B. Each column represents a group, while each row represents a gene transcript. Transcripts are color coded based on log-2fold change from positive (blue) to negative (red). Gray indicates minimal change in expression. 
To identify DE genes effected by ethanol that were rescued by CNO, a Euclidean distance measure clustering was used. The top 47 genes with greatest variability (pairwise Euclidean distance $>1.5$ standard deviations from mean) in expression patterns unique to EtOH (VEH) are illustrated in Figure 3C. Genes in this list tended to be overrepresented in GO categories including thiamine-containing compound metabolic processes, myeloid dendritic cell activation and ammonium transmembrane transport. This indicates that gene expression changes significantly perturbed by bingedrinking effect many a variety of biological pathways in a complex manner.

The results of gene ontology (GO) term enrichment for biological processes are highlighted in Figure 3D. GO annotation of the 688 unique DE genes in $\mathrm{EtOH}(\mathrm{VEH})$ revealed a significant enrichment in genes associated with regulation of $B$ cell differentiation, transocytosis and regulation of T cell mediated immunity among others. Genes overrepresented in these categories are shown in the clustergram in Figure 3D, where enriched terms are the columns, input genes are the rows, and the cell colors in the matrix indicate if a gene is associated with a term (red) based on its combined zscore and p-value. The top 20 overrepresented genes included Zfp36, Zfp63LI, Cd27, BTK, Ikzf3, Inhba, Chrm5, Chrm2, Pfkfb1, Hdac4, Mfsd2a, Cltc, Picalm, Rab11b, Tfap2a, Erbb3, Tjp1, F11r, Was, Trpm4.

Hdac4 was present in all top GO categories. Comparison of the total normalized gene expression of Hdac4 between treatment types is presented in Figure 3E. We observed a significant difference in expression between fluid types receiving vehicle treatment (two-way ANOVA: Fluid $x$ Treatment interaction $-F(1,41)=4.45, p<0.05$; main effect of 
fluid $-\mathrm{F}(1,41)=6.23, \mathrm{p}<0.05$; post-hoc test revealed $\mathrm{EtOH}(\mathrm{VEH})$ vs $\mathrm{H} 2 \mathrm{O}(\mathrm{VEH}), \mathrm{p}<$ 0.05).

To identify the impact of chronic binge-drinking on gene correlation networks,

A.

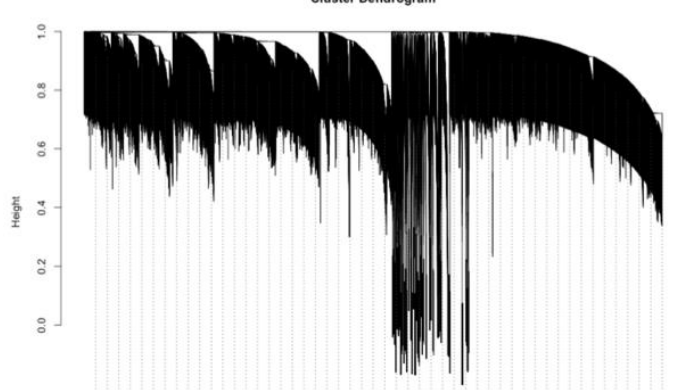

B.

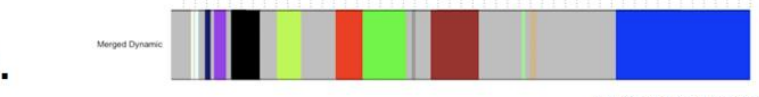

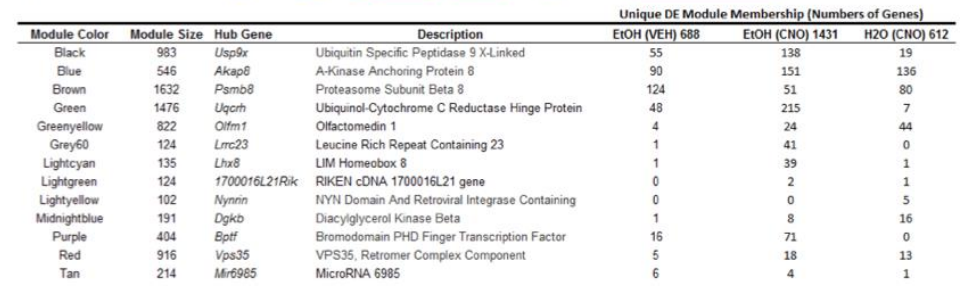

correlation

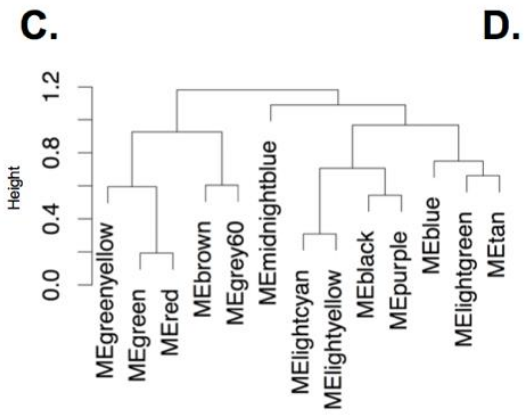

D.

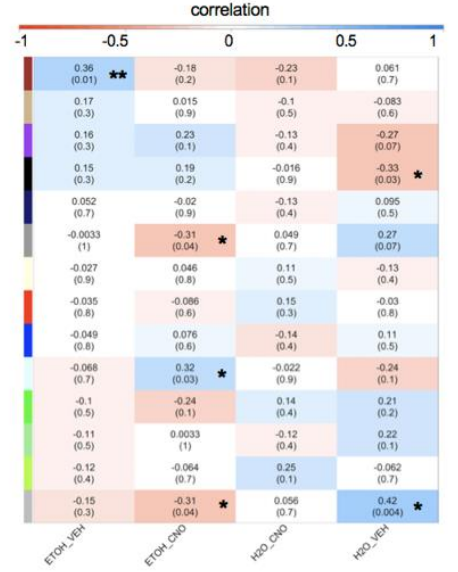

Figure 3. Effects of DREADDs and Drinking on Gene Networks. (A) Gene dendrogram showing the co-expression modules defined by labeled colors. Gene dis-similarity is shown as height. (B) Table describing module characteristics, hub genes and their descriptors, and module membership of unique DEGs identified in Figure 3. (C) Eigengene dendogram showing the correlation of modules as labeled colors corresponding the (B). The dissimilarity of modules is expressed as height. (D) Matrix with the Module-Trait Relationships and corresponding $p$-values between the detected modules on the $y$-axis and fluid type and treatment traits on the $x$-axis. Module-Trait relationships are colored based on their correlation: red is a strong negative correlation, while blue is a strong positive correlation. ${ }^{*} p<0.05,{ }^{* *} p<0.01$.
WGCNA was performed and a

hybrid network was constructed

containing all the same groups

as outlined in DE. The analysis

of 19,671 (out of 24,421 ) genes

identified 13 distinct modules

containing $\sim 100-5000$ genes per

module. The cluster

dendrogram is illustrated in

Figure 4A. Modules are color

coded arbitrarily for clustered

genes expressed across all

treatments and fluid groups.

Gene dissimilarity based on

topological overlap (height) is

assigned to module color. A

table containing genes with the

highest degree of correlation

(hubs) in each module is

presented in Figure 4B. The 
relative module size is tabulated as well as the hub gene description and the number of unique DE genes in each module. Similarity between modules was identified through the clustering of module eigengenes. In Figure 4C, the module eigengene (ME) for each module was calculated and clustered to illustrate intra-modular relationships. Module dissimilarity based on eigengene topological overlap is expressed on the $y$-axis. Increased height corresponds to lower similarity between modules, while decreased height corresponds to increased similarity.

Module susceptibility to group placement was determined by correlating MEs with group placement. Figure 4D illustrates the degree to which a module is correlated with each group. The correlation value is indicated in each cell, with the associated $p$ value directly below. Modules are color coordinated based on correlation from positive (blue) to negative (red). White indicates minimal to no correlation of a module to a group. Only the brown module was found to be significantly, positively correlated to the $\mathrm{EtOH}(\mathrm{VEH})$ condition $(\mathrm{p}<0.01)$. Conversely, three modules were found to be significantly correlated to the $\mathrm{EtOH}(\mathrm{CNO})$ and two to $\mathrm{H} 2 \mathrm{O}(\mathrm{VEH})$. The grey60 module was observed to be negatively correlated in $\mathrm{EtOH}(\mathrm{CNO})(p<0.05)$. The grey module represents unassigned genes, and was found to be significantly correlated to both $\mathrm{EtOH}(\mathrm{CNO})$ (positive, $\mathrm{p}<0.05$ ) and $\mathrm{H} 2 \mathrm{O}(\mathrm{VEH})$ (negative, $\mathrm{p}<0.01$ ). The light cyan module was uniquely positively correlated to $\mathrm{EtOH}(\mathrm{CNO})(p<0.05)$, while the black module was uniquely positively correlated to $\mathrm{H} 2 \mathrm{O}(\mathrm{VEH})(\mathrm{p}<0.05)$. 

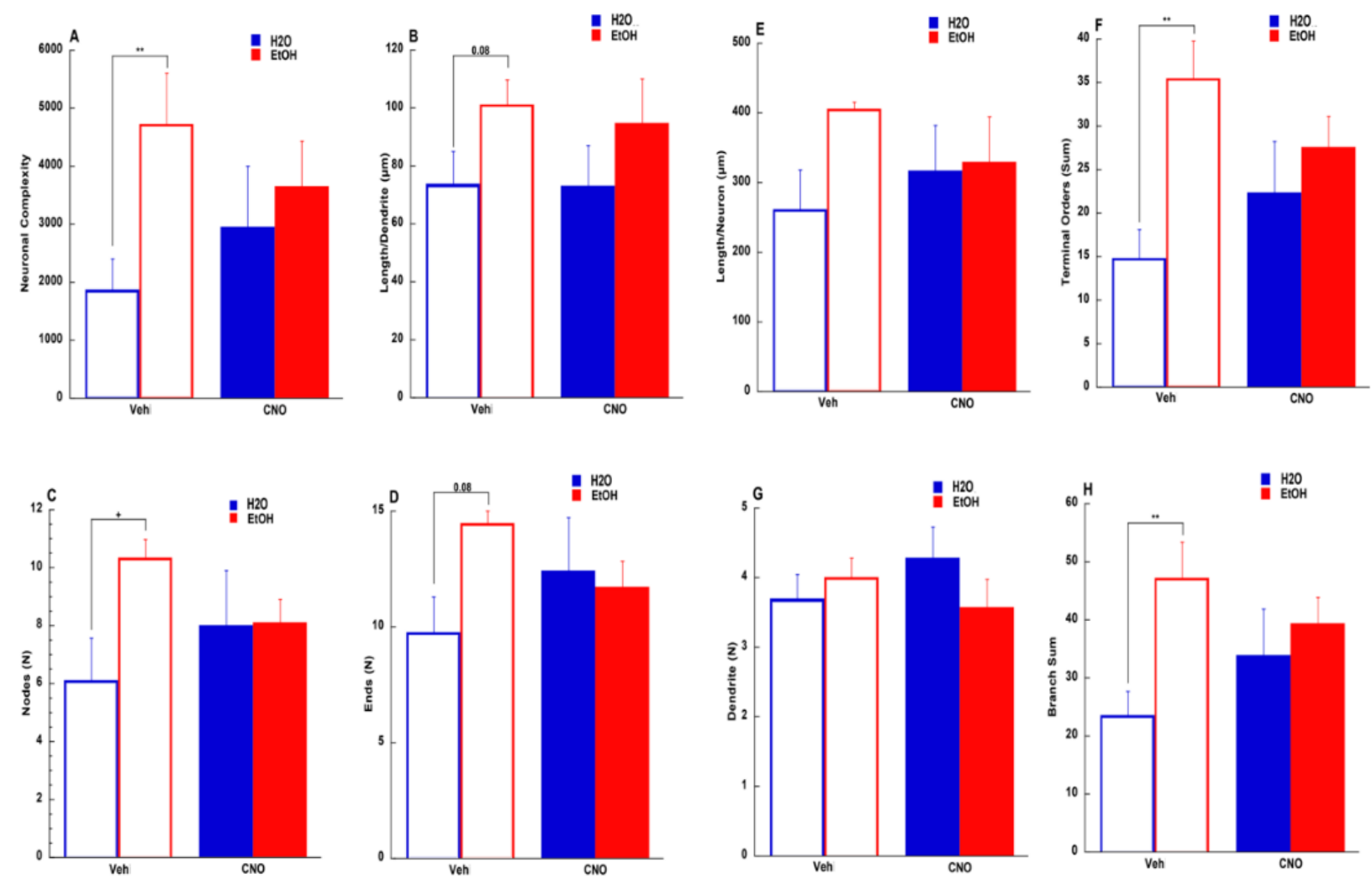

Figure 5. Effects of chronic Gq DREADD stimulation and Drinking on Neuron Morphology. Morphometric parameters analyzed for the dendrites of medium spiny neurons. Morphometric parameters of dendrites of nucleus accumbens medium spiny neurons from adult C57BL/6J mice injected with either $\mathrm{CNO}$ or a vehicle, and exposed to either $\mathrm{EtOH}$ or $\mathrm{H} 2 \mathrm{O}$ were analyzed via Neurolucida Explorer. (A) Complexity, calculated via the equation (sum of terminal orders + number of terminals) * (total dendrite length/number of dendrites). (B) Average dendrite length (total length/dendrite quantity) in $\mu \mathrm{m}$. (C) Number of nodes per neuron. (D) Number of ends per neuron. (E) Total dendrite length per neuron, in $\mu \mathrm{m}$. (F) Sum of the terminal orders (the number of sister branches encountered when tracing a dendrite from the tip back to the cell body). (G) Number of dendrites per neuron. $(\mathbf{H})$ Branch sum per neuron (the total number of segments between nodes, a measure of cell branching). Shown in each graph is the mean \pm the standard error (for neuron number per group see table \#). Multilevel analyses were followed with multiple comparison corrections using the Benjamini-Hochberg approach to adjust p-values to the false discovery rate (FDR) (see table \#). ${ }^{* *} q$-value $<0.01$ (after FDR correction), + = p-value <0.05 (before FDR correction). 
Table 1.

A. Nucleus accumbens medium spiny neurons mophology multilevel analysis

\begin{tabular}{|c|c|c|c|c|c|c|c|c|c|c|}
\hline \multirow{2}{*}{$\begin{array}{l}\text { Morphometric } \\
\text { Parameter }\end{array}$} & \multicolumn{2}{|c|}{ Main Effect $\chi^{2}$} & \multirow{2}{*}{$\begin{array}{c}\text { Interaction } \chi^{2} \\
\text { Treatment-Injection }\end{array}$} & \multirow[b]{2}{*}{ DF } & \multicolumn{2}{|c|}{ Main Effect p-value } & \multirow{2}{*}{$\begin{array}{l}\text { Interaction } \\
\text { p-value } \\
\text { Treatment- } \\
\text { Injection }\end{array}$} & \multicolumn{2}{|c|}{$\begin{array}{l}\text { Main Effect q-value (FDR } \\
\text { Correction) }\end{array}$} & \multirow{2}{*}{$\begin{array}{l}\text { Interaction q-value } \\
\text { (FDR Correction) } \\
\text { Treatment-Injection }\end{array}$} \\
\hline & Treatment & Injection & & & Treatment & Injection & & Treatment & Injection & \\
\hline Complexity & 3.325 & 0.043 & 2.251 & 1 & 0.068 & 0.836 & 0.134 & 0.836 & 0.200 & 0.200 \\
\hline Total Length & 1.308 & $3.46 \mathrm{E}-04$ & 1.633 & 1 & 0.253 & 0.985 & 0.201 & 0.985 & 0.379 & 0.379 \\
\hline Average Length & 2.957 & 0.031 & 0.188 & 1 & 0.086 & 0.861 & 0.665 & 0.257 & 0.861 & 0.861 \\
\hline Nodes & 1.556 & 0.015 & 2.432 & 1 & 0.212 & 0.902 & 0.119 & 0.318 & 0.902 & 0.318 \\
\hline Ends & 0.842 & 0.051 & 3.057 & 1 & 0.359 & 0.821 & 0.080 & 0.538 & 0.821 & 0.241 \\
\hline Branch Sum & 4.025 & 0.178 & 2.332 & 1 & 0.045 & 0.673 & 0.127 & 0.134 & 0.673 & 0.190 \\
\hline Terminal Order & 5.886 & 0.063 & 3.055 & 1 & 0.015 & 0.802 & 0.080 & 0.046 & 0.802 & 0.121 \\
\hline Quantity & 0.851 & 0.250 & 2.166 & 1 & 0.356 & 0.617 & 0.141 & 0.534 & 0.617 & 0.423 \\
\hline
\end{tabular}

B. Benjamin-Hochberg post-hoc analyses

\section{Number of animals and cells per group}

\begin{tabular}{|ccccc|}
\hline Complexity & $\chi^{2}$ & DF & p-value & q-value \\
\hline EtOH+Veh vs. H2O+Veh & 8.051 & 1 & 0.005 & 0.009 \\
EtOH+CNO vs. H2O+CNO & 0.062 & 1 & 0.803 & 0.803 \\
\hline \multicolumn{1}{|l}{} & & & & \\
\hline Average Length & $\chi^{2}$ & DF & p-value & q-value \\
\hline EtOH+Veh vs. H2O+Veh & 4.156 & 1 & 0.041 & 0.083 \\
EtOH+CNO vs. H2O+CNO & 0.828 & 1 & 0.363 & 0.363 \\
\hline
\end{tabular}

\begin{tabular}{|c|ccccccc|}
\hline Group & $\begin{array}{c}\text { Animal } \\
\mathrm{N}\end{array}$ & $\begin{array}{c}\text { Cells/ } \\
\text { Brain \#1 }\end{array}$ & $\begin{array}{c}\text { Cells/ } \\
\text { Brain \#2 }\end{array}$ & $\begin{array}{c}\text { Cells/ } \\
\text { Brain \#3 }\end{array}$ & $\begin{array}{c}\text { Cells/ } \\
\text { Brain \#4 }\end{array}$ & $\begin{array}{c}\text { Cells/ } \\
\text { Brain \#5 }\end{array}$ & $\begin{array}{c}\text { Total } \\
\text { Cells }\end{array}$ \\
\hline H2O+Veh & 4 & 9 & 5 & 6 & 9 & & 29 \\
H2O+CNO & 5 & 5 & 7 & 5 & 6 & 13 & 23 \\
EtOH+Veh & 4 & 6 & 10 & 5 & 8 & & 29 \\
EtOH+CNO & 4 & 6 & 5 & 6 & 6 & & 23 \\
\hline Totals & 17 & \multicolumn{7}{r|}{} & & & & & 104 \\
\hline
\end{tabular}

\begin{tabular}{|ccccc|}
\hline Ends & $\chi^{2}$ & DF & p-value & q-value \\
\hline EtOH+Veh vs. $\mathrm{H} 2 \mathrm{O}+\mathrm{Veh}$ & 5.360 & 1 & 0.021 & 0.082 \\
$\mathrm{EtOH}+\mathrm{CNO}$ vs. $\mathrm{H} 2 \mathrm{O}+\mathrm{CNO}$ & 0.202 & 1 & 0.653 & 0.653 \\
$\mathrm{EtOH}+$ Veh vs. EtOH+CNO & 2.281 & 1 & 0.131 & 0.262 \\
$\mathrm{H} 2 \mathrm{O}+$ Veh vs. $\mathrm{H} 2 \mathrm{O}+\mathrm{CNO}$ & 1.197 & 1 & 0.274 & 0.365 \\
\hline
\end{tabular}

\begin{tabular}{|ccccc|}
\hline Branch Sum & $\chi^{2}$ & DF & p-value & q-value \\
\hline EtOH+Veh vs. H2O+Veh & 8.175 & 1 & 0.004 & 0.008 \\
EtOH+CNO vs. H2O+CNO & 0.141 & 1 & 0.707 & 0.707 \\
\hline
\end{tabular}

\begin{tabular}{|ccccc|}
\hline Sum of Terminal Orders & $\chi^{2}$ & DF & p-value & q-value \\
\hline EtOH+Veh vs. $\mathrm{H} 2 \mathrm{O}+\mathrm{Veh}$ & 10.117 & 1 & 0.001 & 0.006 \\
$\mathrm{EtOH}+\mathrm{CNO}$ vs. $\mathrm{H} 2 \mathrm{O}+\mathrm{CNO}$ & 0.276 & 1 & 0.599 & 0.599 \\
$\mathrm{EtOH}+\mathrm{Veh}$ vs. EtOH+CNO & 1.611 & 1 & 0.204 & 0.311 \\
$\mathrm{H} 2 \mathrm{O}+$ Veh vs. $\mathrm{H} 2 \mathrm{O}+\mathrm{CNO}$ & 1.421 & 1 & 0.233 & 0.311 \\
\hline
\end{tabular}

Table 2.

A. Nucleus accumbens medium spiny neurons sholl area under the curve multilevel analysis

\begin{tabular}{|c|c|c|c|c|c|c|c|c|c|c|}
\hline \multirow{2}{*}{$\begin{array}{c}\text { Morphometric } \\
\text { Parameter }\end{array}$} & \multicolumn{2}{|c|}{ Main Effect $\chi^{2}$} & \multirow{2}{*}{$\begin{array}{c}\text { Interaction } \chi^{2} \\
\text { Treatment-Injection }\end{array}$} & \multirow[b]{2}{*}{ DF } & \multicolumn{2}{|c|}{ Main Effect p-value } & \multirow{2}{*}{$\begin{array}{l}\text { Interaction } \\
\text { p-value } \\
\text { Treatment- } \\
\text { Injection }\end{array}$} & \multicolumn{2}{|c|}{$\begin{array}{l}\text { Main Effect q-value } \\
\text { (FDR Correction) }\end{array}$} & \multirow{2}{*}{$\begin{array}{l}\text { Interaction q-value } \\
\text { (FDR Correction) } \\
\text { Treatment-Injection }\end{array}$} \\
\hline & Treatment & Injection & & & Treatment & Injection & & Treatment & Injection & \\
\hline Intersections & 2.766 & 0.033 & 0.157 & 1 & 0.096 & 0.856 & 0.692 & 0.289 & 0.856 & 0.856 \\
\hline Length & 3.028 & 4.00E-03 & 0.206 & 1 & 0.082 & 0.950 & 0.650 & 0.246 & 0.950 & 0.950 \\
\hline Nodes & 3.755 & 0.004 & 0.552 & 1 & 0.053 & 0.951 & 0.458 & 0.158 & 0.951 & 0.687 \\
\hline Ends & 2.742 & 0.031 & 0.664 & 1 & 0.098 & 0.860 & 0.415 & 0.293 & 0.860 & 0.623 \\
\hline
\end{tabular}

\section{B. Benjamin-Hochberg post-hoc analyses}

\begin{tabular}{|c|c|c|c|c|}
\hline Total Intersections & $x^{2}$ & $\overline{D F}$ & p-value & q-value \\
\hline $\mathrm{EtOH}+\mathrm{Veh}$ vs $\mathrm{H} 2 \mathrm{O}+\mathrm{Veh}$ & 4.123 & 1 & 0.042 & 0.085 \\
\hline $\mathrm{EtOH}+\mathrm{CNO}$ vs. $\mathrm{H} 2 \mathrm{O}+\mathrm{CNO}$ & 1.762 & 1 & 0.184 & 0.184 \\
\hline Total Length & $x^{2}$ & DF & p-value & q-value \\
\hline $\mathrm{EtOH}+\mathrm{Veh}$ vs $\mathrm{H} 2 \mathrm{O}+\mathrm{Veh}$ & 4.404 & 1 & 0.036 & 0.072 \\
\hline $\mathrm{EtOH}+\mathrm{CNO}$ vs. $\mathrm{H} 2 \mathrm{O}+\mathrm{CNO}$ & 1.512 & 1 & 0.219 & 0.219 \\
\hline Total Nodes & $x^{2}$ & DF & p-value & q-value \\
\hline $\mathrm{EtOH}+\mathrm{Veh}$ vs $\mathrm{H} 2 \mathrm{O}+\mathrm{Veh}$ & 5.368 & 1 & 0.021 & 0.041 \\
\hline $\mathrm{EtOH}+\mathrm{CNO}$ vs. $\mathrm{H} 2 \mathrm{O}+\mathrm{CNO}$ & 1.373 & 1 & 0.241 & 0.241 \\
\hline Total Ends & $x^{2}$ & DF & p-value & q-value \\
\hline EtOH+Veh vs $\mathrm{H} 2 \mathrm{O}+\mathrm{Veh}$ & 5.409 & 1 & 0.020 & 0.040 \\
\hline $\mathrm{EtOH}+\mathrm{CNO}$ vs. $\mathrm{H} 2 \mathrm{O}+\mathrm{CNO}$ & 1.309 & 1 & 0.253 & 0.253 \\
\hline
\end{tabular}


Behavioral plasticity can be observed on a morphological level. Therefore, we analyzed medium spiny neurons in the nucleus accumbens for a variety of morphometric parameters, in order to determine the effects of treatment (CNO or vehicle), fluid type (EtOH or $\mathrm{H} 2 \mathrm{O}$ ), or whether there was an interaction between the two treatments. We analyzed neuronal complexity, determined via the equation (sum of terminal orders + number of terminals) ${ }^{*}$ (total dendritic length/number of dendrites) (Figure 5A), length per dendrite (Figure 5B), number of nodes (Figure $5 \mathrm{C}$ ), number of ends (Figure 5D), total length per neuron (Figure 5E), the sum of terminal orders, which is defined as the number of sister branches encountered when tracing a dendrite from the tip back to the cell body (Figure 5F), the quantity of dendrites (Figure 5G), and the branch sum, defined as the total number of segments between nodes (Figure $5 \mathrm{H}$ ). In most parameters, there was an increase following exposure to EtOH (statistics for the analyses can are listed in Table 1). This effect was significant following corrections for multiple comparisons in neuronal complexity, the sum of terminal orders, and the branch sum, approached significance following corrections for multiple comparisons in the length per dendrite and the number of ends, and was significant before corrections for multiple comparisons in the number of nodes (Table 1). There was no significant change in the total dendritic length or the number of dendrites. There was also no effect of the injection (CNO or Vehicle), nor was there an interaction between the injection and exposure conditions. However, it is worth noting that the effect of EtOH was no longer seen after CNO injection. 

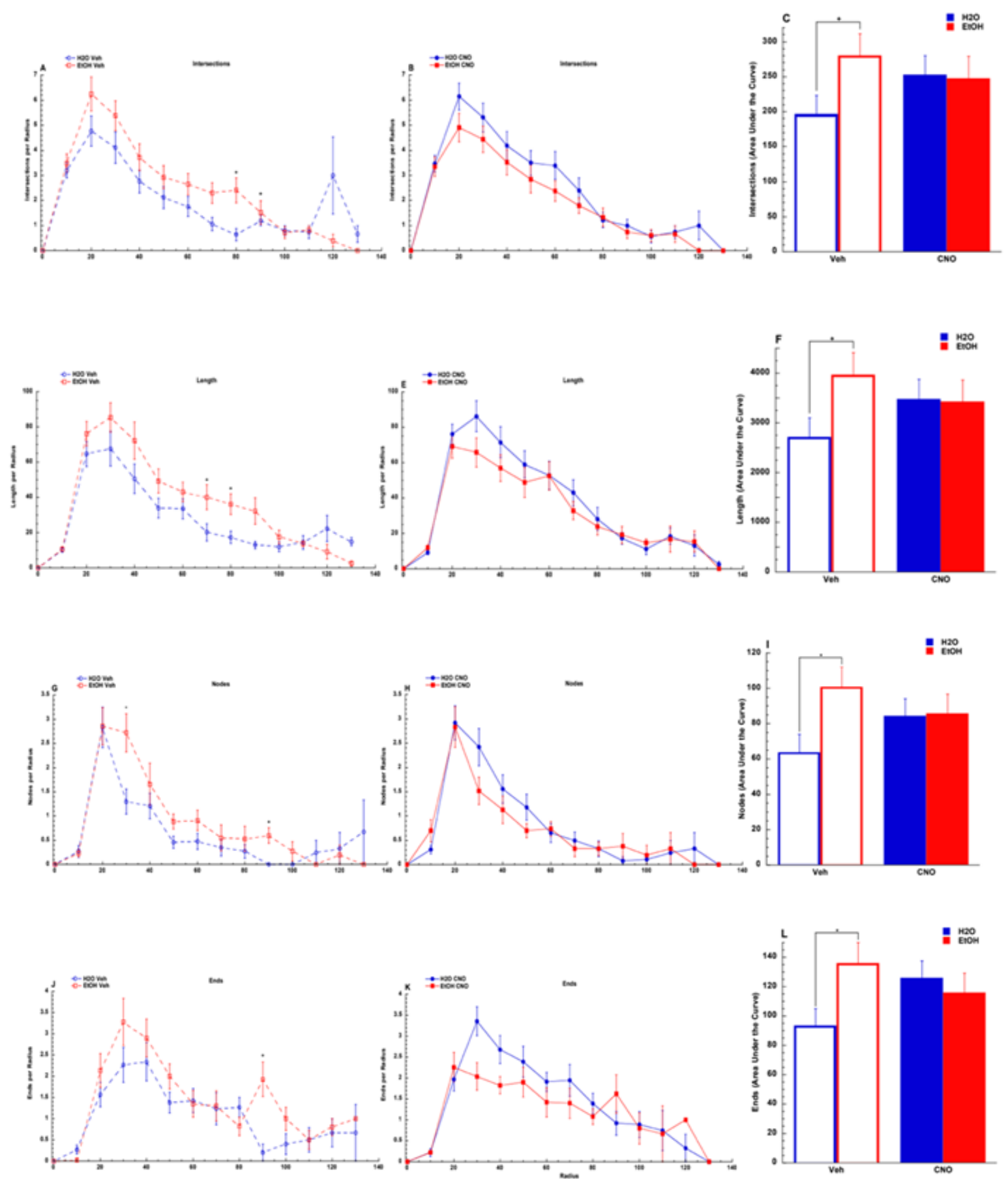

Figure 6. Sholl analysis and area under the curve analyzed for the dendrites of medium spiny neurons. Sholl analysis and area under the curve (AUC) of dendrites of nucleus accumbens medium spiny neurons from HDID-1 mice injected with either $\mathrm{CNO}$ or a vehicle, and exposed to either $\mathrm{EtOH}$ or $\mathrm{H} 2 \mathrm{O}$ were analyzed with Neurolucida Explorer. Radii were $10 \mu \mathrm{m}$ each. Intersections per radius of $\mathrm{H} 2 \mathrm{O}$ Veh vs. EtOH Veh (A), H2O CNO vs. EtOH CNO $(\mathbf{B})$, and $\mathrm{AUC}(\mathbf{C})$. Length per radius of $\mathrm{H} 2 \mathrm{O}$ Veh vs. EtOH Veh (D), H2O CON vs. EtOH CNO (E), and AUC (F). Nodes per radius of $\mathrm{H} 2 \mathrm{O}$ Veh vs. EtOH Veh $(\mathbf{G}), \mathrm{H} 2 \mathrm{O} \mathrm{CNO}$ vs. EtOH CNO (H) and AUC (I). Ends per radius of $\mathrm{H} 2 \mathrm{O}$ Veh vs. EtOH Veh (J), H2O CNO vs. EtOH CNO (K) and AUC (L). Shown in each graph is the mean \pm the standard error of the mean. Multilevel analyses by radius $(\mathbf{A}, \mathbf{B}, \mathbf{D}, \mathbf{E}, \mathbf{G}, \mathbf{H}, \mathbf{J}, \mathbf{K})$ or for the total area $(\mathbf{C}, \mathbf{F}, \mathbf{I}, \mathbf{L})$ were followed with multiple comparisons corrections using the Benjamini-Hochberg approach to adjust $p$-values to the false discovery rate (FDR) (see table \#1). * q-value $<0.05$ (after FDR correction), $+=$ p-value $<0.05$ (before FDR correction). 
We also performed sholl analyses for these same neurons. We analyzed intersections (Figure 6A,B), length (Figure 6D,E), nodes (Figure 6G,H) and ends (Figure $6 \mathrm{~J}, \mathrm{~K})$ by radius $(10 \mu \mathrm{m})$, and examined each radius individually with multilevel analyses and corrections for multiple comparisons. As the primary effect seen in the neuron summary was an effect of $\mathrm{EtOH}$ in the vehicle injection condition, this is the comparison that we focused on. There were only sporadic significant differences in radii, with no overall pattern of effects in any variable (statistics for the analyses are listed in Table 2). Therefore, we elected to also examine the area under the curve (AUC). In this analysis, we found a similar effect as we did with the morphometric parameter analysis, as there was a greater $\mathrm{AUC}$ in the $\mathrm{EtOH}$ exposed groups when compared with $\mathrm{H} 2 \mathrm{O}$ exposed groups, an effect which was significant in the nodes (Figure 6I) and ends (Figure 6L), and approached significance in intersections (Figure 6C) and length (Figure 6F). Also similar to the morphometric parameter analysis was that this difference between $\mathrm{EtOH}$ and $\mathrm{H} 2 \mathrm{O}$ exposure was no longer seen in the $\mathrm{CNO}$ injection condition, although there was no interaction between the injection and exposure, or effect of the injection.

\section{Experiment 3: Pharmacologically testing the role of the overrepresented gene,}

\section{Hdac4, in binge-like drinking}


The effects of HDAC4/5 inhibitor, LMK-235, on binge-like alcohol drinking were modest, but significant. Interestingly, they developed over several days and treatments (suggesting transcriptional mechanisms). When comparing ethanol intake across baseline and treatment weeks, a two way ANOVA revealed a significant main effect of treatment period on ethanol intake (Figure $7 A ; F(2,152)=5.16, p<0.01$ ). Previous work has shown that the HDAC4/5 inhibitor, LMK-235, requires several administrations to exert its effects on signaling and morphology. We followed up on this finding by calculating a change score for each animal (by subtracting the average intake during treatment week 1 or week 2 from the average intake during baseline; shown in Figure 7B). Two way ANOVA (dose $x$ treatment week) revealed a significant main effect of dose and a significant main effect of treatment week [dose: $F(2,76)=3.60, p<0.05$; treatment week: $F(1,76)=2.44, p<0.05]$.

A.

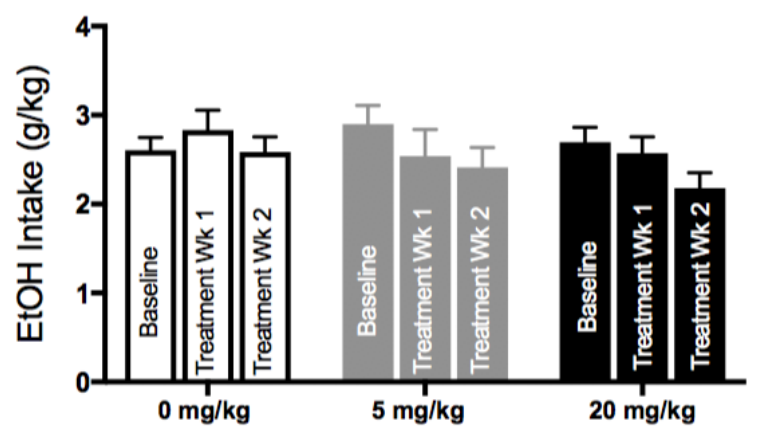

B.

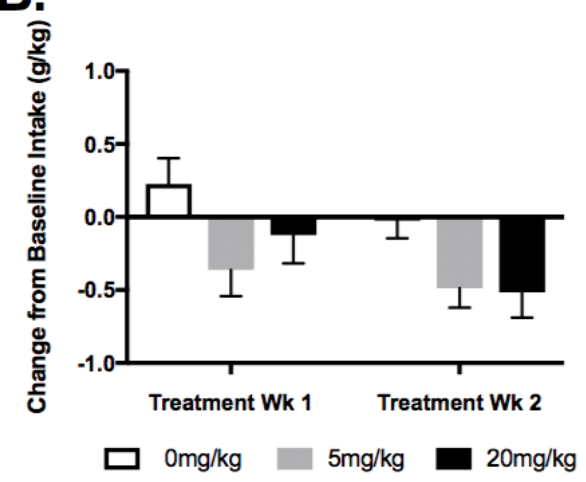

Figure 7. Treatment with HDAC4/5 inhibitor, LMK-235, reduced binge-like alcohol drinking. (A) Average weekly ethanol intake after treatment with 0,5 or $20 \mathrm{mg} / \mathrm{kg}$ LMK-235. Two way ANOVA revealed a significant main effect of treatment period on ethanol intake (Figure 7A; $F(2,152)=5.16, p<0.01)$. (B) Ethanol intake presented as average difference score from baseline intake for each treatment week. Here significant reductions were observed for both doses over a two-week period [Two way ANOVA (dose $x$ treatment week) revealed a significant main effect of dose and a significant main effect of treatment week [dose: $F(2,76)=3.60, p<0.05$; treatment week: $F(1,76)=2.44, p<0.05$ ]. 


\section{DISCUSSION}

Despite its prevalence, those suffering from AUD often receive limited or no treatment. Currently, 3 FDA-approved medications are available for treatment: disulfiram, acamprosate and naltrexone (51). However, these medications are often underutilized, only work in a fraction of treated individuals to improve health outcomes, and improvements do not last beyond treatment (52). Further, although DBS of the NAc appears to be a potentially promising therapeutic approach, it is quite invasive and does not produce lasting reductions in drinking or craving. Thus, it is clear there exists a need for therapeutic approaches which produce robust and lasting effects. Here, we have shown that chronic binge-drinking induces lasting changes in gene expression networks and neuronal morphology, which can be ameliorated via chronic stimulation of $\mathrm{Gq}$ signaling (via CNO/hM3Dq) in the NAc. Further, we found that we could pharmacologically target HDAC4, a gene that is altered with chronic binge-like drinking and ameliorated with $\mathrm{CNO} / \mathrm{hM} 3 \mathrm{Dq}$, to reduce binge drinking.

\section{Animal Models of Binge Drinking and DREADDs}

We and others have previously used HDID-1 mice as a reliable and predictive genetic model for high intensity binge-like drinking. This is due to their ability to achieve pharmacologically relevant blood alcohol levels (BALs), exhibit behavioral impairment after binge-like drinking and exhibit relapse and withdrawal behavior following binge sessions (6). Critically, it has been shown that genetic selection has not altered the preference of mice to other tastants, as well as their ability to metabolize alcohol (53). The DID paradigm was employed for its high-throughput, limited access approach which 
does not require the use of tastants to motivate high levels of ethanol consumption during the dark cycle when ingestive behavior is high. In our study, we observed robust reductions in ethanol intake of female HDID-1 mice expressing hM3Dq in the NAc when treated with CNO during a DID limited access paradigm. These effects were observed for the entirety of the CNO treatment period (28 days), suggesting mice expressing hM3Dq in the NAc did not develop tolerance or show sensitization in response to chronic treatment with $\mathrm{CNO}$. Moreover, the decreased intake persisted for at least 7 days during the vehicle "washout" period. We did not observe any change in ethanol drinking for mice expressing GFP or hM4Di in the NAc, suggesting our findings are specific to mice expressing hM3Dq. Purohit et al. (2018) showed that when CNO was administered acutely (2 days) or chronically (7 days) to C57BL/6J females, only mice expressing hM3Dq in the NAc showed reductions in binge-like drinking (36). This underscores that our findings are generalizable to more than one strain of mice. However, there may exist sex differences, or paradigm specific effects, in the effects of CNO/DREADDs for the NAc. Cassataro et al. (2014) found that CNO reduced binge-like drinking in C57BL/6J males (23). However, direct comparison of these studies should be cautioned since CNO was administered IP in the current study, as well as in Purohit et al. (2018), and via tap water in Cassataro et al. $(2014)(23,36)$. We are currently following up on these differences by conducting studies with both males and females to evaluate the role of sex as a biological factor. Similar studies that have been previously conducted in female C57BL/6J mice have shown that CNO injections do not impact water intake when comparing between mice expressing GFP, hM4Di, or hM3Dq in the NAc (36). Taken together, these results build strong evidence to suggest that chronic 
stimulation of the NAC in HDID-1 female mice produced behavioral plasticity resulting in lasting reductions of binge-like drinking.

\section{Effects of Chronic Binge-Drinking and DREADDs on the NAc Transcriptome}

Reductions in ethanol consumption observed during the washout period of the DID paradigm suggest lasting, plastic changes resulting due to chronic neuronal stimulation in mice expressing hM3Dq. Transcriptomic analyses were used to identify genes associated with binge-like drinking of ethanol which were ameliorated by CNO. Using Differential Expression analysis (DE), genes with significantly altered levels of expression were identified and contextualized within biological networks using Gene ontology analysis (GO). Weighted gene covariance network analysis (WGCNA) was used to construct a scale free network and identify modules. Genes with a high degree of network connectivity (hubs) that correlated with binge-like drinking were used to identify candidate biomarkers and therapeutic targets. Gene overlap identified from DE implicated changes in gene expression that were either treatment or/and fluid type specific. The 688 genes changed solely in the group $\mathrm{EtOH}(\mathrm{VEH})$ indicate genes whose expression was perturbed exclusively by chronic binge-like alcohol drinking. This is the first time that NAc transcriptomic changes related exclusively to either chronic bingedrinking or chronic CNO stimulation of hM3Dq have been identified. For $\mathrm{EtOH}(\mathrm{CNO})$, 1,431 genes were found to be related exclusively to those genes ameliorated by CNO treatment. Further, 612 genes were identified in the $\mathrm{H} 2 \mathrm{O}$ (CNO) group and represented genes that were related exclusively to $\mathrm{CNO}$ treatment alone. 
Progression from acute to chronic alcohol intake, incites changes in gene expression levels that occur to maintain homeostasis under the increasing burden placed on the system by alcohol (54). Chronic exposure to alcohol causes dysregulation of these homeostatic mechanisms leading to alcohol abuse and dependence. In our work, we observed that of the 688 genes uniquely differentially expressed in the $\mathrm{EtOH}$ (VEH) group, those exhibiting the most extreme changes in expression, exhibited relatively reversed expression changes relative to the $\mathrm{EtOH}(\mathrm{CNO})$ and $\mathrm{H} 2 \mathrm{O}(\mathrm{CNO})$ groups. We took this approach to identify genes which were explicitly changed by chronic binge drinking and ameliorated by CNO. Previous groups have observed similar outcomes in ethanol self-administration. In 2011, Mulligan et al, observed significant changes in gene expression in brain regions such as the striatum. They identified candidate genes and pathways altered by initial alcohol selfadministration by measuring global brain gene expression (using microarrays) in alcohol-preferring male C57BL/6J mice after a single bout of binge-like drinking (DID). Using DE analysis, they found that acute alcohol intake resulted in small, but consistent, changes in gene expression. Here, we found similar results; consistent changes in gene expression that were visualized in heat maps between groups were present across all groups relative to their treatment. Further, we observed many of the same unique differentially and co-expressed genes in both the EtOH (VEH) and EtOH (CNO) groups as those observed within the striatum by Mulligan et al; further supporting and validating the current findings.

$\mathrm{GO}$ analysis of DE genes identified for the $\mathrm{EtOH}(\mathrm{VEH})$ group identified the importance of Hdac4 expression in binge drinking. In pathways such as regulation of B- 
cell differentiation, transcytosis and regulation of T cell mediated immunity Hdac4 was consistently found to be overrepresented. Additionally, we observed gene representation related to circadian and neuroimmune pathways such as others have previously reported (55-57). Because Hdac4 was present in the majority of significant GO pathways, we took this to mean that Hdac4 played a large role in a number of biological pathways related to chronic binge drinking.

We created a consensus network using WGCNA and identified that clustered modules were correlated to treatment and fluid groups. Here, treatment groups were treated as traits. $\mathrm{EtOH}(\mathrm{VEH})$ was considered to be the binge drinking trait without treatment, $\mathrm{EtOH}(\mathrm{CNO})$ binge drinking with treatment and $\mathrm{H} 2 \mathrm{O}(\mathrm{CNO})$ treatment with CNO alone. Modules (containing groups of genes) significantly correlated to treatments were identified as being driven by a particular trait. In this way, most of the genes in a given module significantly correlated to a certain trait, would also exhibit a correlation with the trait of the same sign as the eigengene. The eigengene-trait correlation measured the strength and direction of association between the module (the representative profile) and the trait. Thus, if this was positive (or negative), it implied that the trait increased (or decreased) with increasing eigengene "expression". For example, the brown module was significantly correlated to the EtOH (VEH) trait [but not the EtOH (CNO) or $\mathrm{H} 2 \mathrm{O}(\mathrm{CNO})$ traits], thus binge drinking was being driven positively by the majority of genes in the brown module. Interestingly, there were no modules significantly correlated with CNO. This implied that CNO had no significant impact on correlated gene changes and thus may have little to no significant effect on biological processes. This result is further supported previously by groups such as Jendryka et al., 
(2019) which showed that the conversion of CNO off targets are minimal at $1-5 \mathrm{mg} / \mathrm{kg}$ dosing (58). Thus, we infer that CNO alone present little to no significant impact on gene correlations. Further, we used our data set to query the LINCS L1000 database (59) and found low connectivity with clozapine, suggesting there no significant contribution from back metabolism of CNO to clozapine.

Hdac4 was identified in the black module. This module was found to be significantly positively correlated to the $\mathrm{H} 2 \mathrm{O}$ (VEH) trait, while being negatively correlated to the EtOH (VEH) trait. By nature, trait and module correlation is directly related to gene expression. Thus, this inverse correlation suggests that changes in gene expression are directly related to a difference in trait correlation. This implies that if Hdac4 expression were changed, it (as a regulatory gene) would induce a cascade of expression changes (in this particular differentially correlated module) that could ameliorate changes induced by binge drinking. The black module Hub is the gene Usp9x (Ubiquitin Specific Peptidase $9 \mathrm{X}$-linked or Deubiquitinase). Deubiquitinase is involved both in the processing of ubiquitin precursors and of ubiquitinated proteins. Thus, it may, play an important regulatory role at the level of protein turnover by preventing degradation of proteins through the removal of conjugated ubiquitin (60). Interestingly, GO analysis for transcription factors in this module revealed $\mathrm{Hdac4}$ and Usp9x among other genes were highly over represented for the transcription factors Ctnnb1 and Jun. Both transcription factors regulate many genes with numerous, complex roles in cellular processes. Interestingly, although $\mathrm{Hdac} 4$ is not the primary hub gene within the black module, it is modulated by the same transcription factors as the hub gene and participates in a similar biological pathway. Thus, we infer that changing 
the expression of either of these genes would impact the overall correlation of the module they are found in to a particular trait. This result presents a significant finding for further pharmacological targeting of genes that participate in this module in order to ameliorate gene expression changes that are caused by binge-drinking. Taken together, these transcriptomic findings have resulted in the identification of $\mathrm{Hdac} 4$ and other genes, such as Usp9x, in this black module as important for amelioration of gene expression related to alcohol use disorders.

\section{Effects of Binge-Drinking and DREADDs on NAc Neuronal Morphology}

We found that chronic binge-like drinking resulted in increased complexity of medium spiny neurons in the NAc, an effect that was ameliorated by chronic treatment with CNO. Interestingly and unexpectedly, no effect of CNO was observed in water drinking mice, suggesting that chronically increasing Gq signaling in the NAc does not produce robust and lasting changes in neuronal complexity. We were unable to identify any published reports on the effects of DID or binge-like drinking on neuronal morphology in the NAc (or any other brain region) for comparison. However, there are several published studies evaluating the effects of chronic intermittent ethanol vapor on neuronal morphology in different brain regions. Most relevant to this work are studies by Wang et al. (2015), Uys et al. (2016), and DePoy et al. (2013) evaluating the effects of CIE on aspects of neuronal morphology in the dorsal and ventral striatum (61-63). In brief, these studies report that CIE results in increased spine density, increased dendritic diameter, increased dendritic length and number of processes. Although binge-like drinking in DID is likely modeling different aspects of AUD than CIE, it 
appears that both alcohol models result in morphological changes in the striatum that manifest as increased neuronal complexity, or dendritic hypertrophy.

\section{Pharmacologically Targeting HDAC4 to Reduce Binge-Like Drinking}

It has been shown that alcohol and withdrawal result in a global reduction of expressed transcripts, accompanied by an increase in expressed transcripts coding for regulators of epigenetic silencing (64). One such class of enzymes, histone deacetylases (HDAC; transcriptionally silencing enzymes), are inhibited by valproate. Valproate treatment during alcohol withdrawal reduces anxiety in dependent animals (65). Simon-O'Brien et al. (2012) reported that several classes of HDAC inhibitors and DNA methyltransferase inhibitors decrease alcohol-seeking behaviors (66). Thus, there is growing evidence that epigenetic modifiers and changes in gene expression play a role in alcohol behaviors. Here, we showed that the HDAC4/5 inhibitor LMK 235 reduced binge-like drinking in mice selectively bred to drink to intoxication. Based on these results, we inferred that there were changes in transcriptional mechanisms because we observed that reductions in intake developed over several days and treatments. Although Hdac4 was selected as a target based on transcriptomic data from female mice, the compound reduced ethanol drinking in both male and female mice. Others have shown that HDAC4 is regulated by neuronal activity and plasticity, and inhibiting HDAC4 via LMK 235 can alter neuronal morphology (67-69). 


\section{Summary and Future Directions}

We chronically stimulated the nucleus accumbens in mice via CNO/DREADDs, which resulted in lasting reductions in high-intensity, binge-like alcohol drinking in mice. We were able to identify and target specific molecular pathways altered by alcohol but rescued by excitatory DREADDs using pharmacology (HDAC4/5 inhibitor) to mimic the behavioral effects of DREADDs and reduce binge drinking. Ongoing work is focused on using this data to identify and test compounds with high clinical translational potential.

\section{FUNDING}

To ARO: US Department of Veterans Affairs Awards IK2BX002488, NIH INIANeuroimmune U01 AA10760 and R03AA026997, Andrews Genomics Fund, NARSAD Young Investigator Award, Collins Medical Trust. To DYP: Build EXITO program, Grant 5TL4GM118965, Ronald E. McNair Scholar Program.

\section{DISCLOSURES}

ARO, DYP have nothing to disclose.

\section{ACKNOWLEDGEMENTS}

This paper gratefully acknowledges the help and support provided by the following people: Ovidiu (Dan) lancu, John Crabbe, Robert Hitzemann, Robert Searles, Miranda Lim, Sean P. Farris, Callie Goeke, Evan J. Firsick, Kayla G. Townsley, Marina Guizzetti. 


\section{CITATIONS}

1. Rhodes JS, Best K, Belknap JK, Finn DA, Crabbe JC (2005): Evaluation of a simple model of ethanol drinking to intoxication in C57BL/6J mice. Physiol Behav. 84: 5363.

2. Rhodes JS, Ford MM, Yu CH, Brown LL, Finn DA, Garland T, Crabbe JC (2007): Mouse inbred strain differences in ethanol drinking to intoxication. Genes, Brain Behav. 6: 1-18.

3. Crabbe JC (2012): Translational behaviour-genetic studies of alcohol: are we there yet? Genes Brain Behav. 11: 375-86.

4. Crabbe JC, Metten P, Rhodes JS, Yu C-H, Brown LL, Phillips TJ, Finn DA (2009): A line of mice selected for high blood ethanol concentrations shows drinking in the dark to intoxication. Biol Psychiatry. 65: 662-70.

5. Crabbe JC, Metten P, Belknap JK, Spence SE, Cameron AJ, Schlumbohm JP, et al. (2014): Progress in a replicated selection for elevated blood ethanol concentrations in HDID mice. Genes, Brain Behav. 13: 236-246.

6. Barkley-Levenson AM, Crabbe JC (2014, May): High Drinking in the Dark Mice: A genetic model of drinking to intoxication. Alcohol. 48.

7. Crabbe JC, Metten P, Savarese AM, Ozburn AR, Schlumbohm JP, Spence SE, Hack WR (2019): Ethanol Conditioned Taste Aversion in High Drinking in the Dark Mice. Brain Sci. 9: 2.

8. Ferguson LB, Ozburn AR, Ponomarev I, Metten P, Reilly M, Crabbe JC, et al. (2018): Genome-Wide Expression Profiles Drive Discovery of Novel Compounds that Reduce Binge Drinking in Mice. Neuropsychopharmacology. 43: 1257-1266. 
9. Iancu OD, Oberbeck D, Darakjian P, Metten P, McWeeney S, Crabbe JC, Hitzemann R (2013): Selection for Drinking in the Dark Alters Brain Gene Coexpression Networks. Alcohol Clin Exp Res. 37: 1295-1303.

10. Hitzemann R, Oberbeck D, lancu O, Darakjian P, McWeeney S, Spence S, et al. (2017): Alignment of the transcriptome with individual variation in animals selectively bred for High Drinking-In-the-Dark (HDID). Alcohol. 60: 115-120.

11. Tipps ME, Moschak TM, Mitchell SH (2014): Behavioral disinhibition in mice bred for high drinking in the dark (HDID) and HS controls increases following ethanol. Drug Alcohol Depend. 136: 149-152.

12. McCulley WD, Ascheid S, Crabbe JC, Rosenwasser AM (2013): Selective breeding for ethanol-related traits alters circadian phenotype. Alcohol. 47: 187-94.

13. Barkley-Levenson AM, Cunningham CL, Smitasin PJ, Crabbe JC (2015): Rewarding and aversive effects of ethanol in High Drinking in the Dark selectively bred mice. Addict Biol. 20: 80-90.

14. Barkley-Levenson AM, Crabbe JC (2015): Distinct ethanol drinking microstructures in two replicate lines of mice selected for drinking to intoxication. Genes, Brain Behav. 14: 398-410.

15. Barkley-Levenson AM, Crabbe JC (2015): Genotypic and sex differences in anxietylike behavior and alcohol-induced anxiolysis in High Drinking in the Dark selected mice. Alcohol. 49: 29-36.

16. Kamdar NK, Miller SA, Syed YM, Bhayana R, Gupta T, Rhodes JS (2007): Acute effects of naltrexone and GBR 12909 on ethanol drinking-in-the-dark in C57BL/6J mice. Psychopharmacology (Berl). 192: 207-17. 
17. Kasten CR, Blasingame SN, Boehm SL (2015): Bidirectional enantioselective effects of the GABAB receptor agonist baclofen in two mouse models of excessive ethanol consumption. Alcohol. 49: 37-46.

18. Navarro M, Carvajal F, Lerma-Cabrera JM, Cubero I, Picker MJ, Thiele TE (2015):

Evidence that Melanocortin Receptor Agonist Melanotan-II Synergistically

Augments the Ability of Naltrexone to Blunt Binge-Like Ethanol Intake in Male C57BL/6J Mice. Alcohol Clin Exp Res. 39: 1425-1433.

19. Crabbe JC, Ozburn AR, Metten P, Barkley-Levenson A, Schlumbohm JP, Spence SE, et al. (2017): High Drinking in the Dark (HDID) mice are sensitive to the effects of some clinically relevant drugs to reduce binge-like drinking. Pharmacol Biochem Behav. 160: 55-62.

20. Zhou Y, Leri F, Low MJ, Kreek MJ (2019): Sex differences in the effect of bupropion and naltrexone combination on alcohol drinking in mice. Pharmacol Biochem Behav. 181: 28-36.

21. Ozburn AR, Harris RA, Blednov YA (2013): Chronic voluntary alcohol consumption results in tolerance to sedative/hypnotic and hypothermic effects of alcohol in hybrid mice. Pharmacol Biochem Behav. 104: 33-39.

22. Koob GF, Volkow ND (2010): Neurocircuitry of Addiction.

Neuropsychopharmacology. 35: 217-238.

23. Cassataro D, Bergfeldt D, Malekian C, Van Snellenberg JX, Thanos PK, Fishell G, Sjulson L (2014): Reverse Pharmacogenetic Modulation of the Nucleus Accumbens Reduces Ethanol Consumption in a Limited Access Paradigm.

Neuropsychopharmacology. 39: 283-290. 
24. He F, Guan H, Zhao Z, Miao X, Zhou Q, Li L, et al. (2008): Evaluation of Short-Term Psychological Functions in Opiate Addicts after Ablating the Nucleus Accumbens via Stereotactic Surgery. Stereotact Funct Neurosurg. 86: 320-329.

25. Wu H-M, Wang X-L, Chang C-W, Li N, Gao L, Geng N, et al. (2010): Preliminary findings in ablating the nucleus accumbens using stereotactic surgery for alleviating psychological dependence on alcohol. Neurosci Lett. 473: 77-81.

26. Pierce RC, Vassoler FM (2013): Deep brain stimulation for the treatment of addiction: basic and clinical studies and potential mechanisms of action. Psychopharmacology (Berl). 229: 487-491.

27. Heinze H-J, Heldmann M, Voges J, Hinrichs H, Marco-Pallares J, Hopf J-M, et al. (2009): Counteracting incentive sensitization in severe alcohol dependence using deep brain stimulation of the Nucleus accumbens: clinical and basic science aspects. Front Hum Neurosci. 3: 22.

28. Kuhn J, Gründler TOJ, Bauer R, Huff W, Fischer AG, Lenartz D, et al. (2011): Successful deep brain stimulation of the nucleus accumbens in severe alcohol dependence is associated with changed performance monitoring. Addict Biol. 16: $620-623$.

29. Voges J, Müller U, Bogerts B, Münte T, Heinze H-J (2013): Deep Brain Stimulation Surgery for Alcohol Addiction. World Neurosurg. 80: S28.e21-S28.e31.

30. Knapp CM, Tozier L, Pak A, Ciraulo DA, Kornetsky C (2009): Deep brain stimulation of the nucleus accumbens reduces ethanol consumption in rats. Pharmacol Biochem Behav. 92: 474-479.

31. Henderson MB, Green AI, Bradford PS, Chau DT, Roberts DW, Leiter JC (2010): 
Deep brain stimulation of the nucleus accumbens reduces alcohol intake in alcoholpreferring rats. Neurosurg Focus. 29: E12.

32. Guo L, Zhou H, Wang R, Xu J, Zhou W, Zhang F, et al. (2013): DBS of nucleus accumbens on heroin seeking behaviors in self-administering rats. Drug Alcohol Depend. 129: 70-81.

33. Ma Y, Chen N, Wang H-M, Meng F-G, Zhang J-G (2013): Inhibition of the reinstatement of morphine-induced place preference in rats by high-frequency stimulation of the bilateral nucleus accumbens. Chin Med J (Engl). 126: 1939-43.

34. Vassoler FM, Schmidt HD, Gerard ME, Famous KR, Ciraulo DA, Kornetsky C, et al. (2008): Deep Brain Stimulation of the Nucleus Accumbens Shell Attenuates Cocaine Priming-Induced Reinstatement of Drug Seeking in Rats. J Neurosci. 28: 8735-8739.

35. Ho AL, Salib A-MN, Pendharkar A V., Sussman ES, Giardino WJ, Halpern CH (2018): The nucleus accumbens and alcoholism: a target for deep brain stimulation. Neurosurg Focus. 45: E12.

36. Purohit K, Parekh PK, Kern J, Logan RW, Liu Z, Huang Y, et al. (2018):

Pharmacogenetic Manipulation of the Nucleus Accumbens Alters Binge-Like Alcohol Drinking in Mice. Alcohol Clin Exp Res. 42: 879-888.

37. Bayram-Weston Z, Olsen E, Harrison DJ, Dunnett SB, Brooks SP (2016): Optimising Golgi-Cox staining for use with perfusion-fixed brain tissue validated in the zQ175 mouse model of Huntington's disease. J Neurosci Methods. 265: 81-8.

38. Andrews S (2014): FastQC A Quality Control tool for High Throughput Sequence Data. http://www.bioinformatics.babraham.ac.uk/projects/fastqc/. . 
39. Dobin A, Davis CA, Schlesinger F, Drenkow J, Zaleski C, Jha S, et al. (2013):

STAR: ultrafast universal RNA-seq aligner. Bioinformatics. 29: 15-21.

40. Anders S, Pyl PT, Huber W (2015): HTSeq--a Python framework to work with highthroughput sequencing data. Bioinformatics. 31: 166-9.

41. Development Core Team R (2011): R: A Language and Environment for Statistical Computing. R Found Stat Comput. (Vol. 1).

42. Law CW, Chen Y, Shi W, Smyth GK (2014): voom: precision weights unlock linear model analysis tools for RNA-seq read counts. Genome Biol. 15: R29.

43. Hulsen T, de Vlieg J, Alkema W (2008): BioVenn - a web application for the comparison and visualization of biological lists using area-proportional Venn diagrams. BMC Genomics. 9: 488.

44. Langfelder P, Horvath S (2008): WGCNA: an R package for weighted correlation network analysis. BMC Bioinformatics. 9: 559.

45. Tritchler D, Parkhomenko E, Beyene J (2009): Filtering Genes for Cluster and Network Analysis. BMC Bioinformatics. 10: 193.

46. Kuleshov M V., Jones MR, Rouillard AD, Fernandez NF, Duan Q, Wang Z, et al. (2016): Enrichr: a comprehensive gene set enrichment analysis web server 2016 update. Nucleic Acids Res. 44: W90-W97.

47. Chen EY, Tan CM, Kou Y, Duan Q, Wang Z, Meirelles G, et al. (2013): Enrichr: interactive and collaborative HTML5 gene list enrichment analysis tool. BMC Bioinformatics. 14: 128.

48. Aarts E, Verhage M, Veenvliet J V, Dolan C V, van der Sluis S (2014): A solution to dependency: using multilevel analysis to accommodate nested data. Nat Neurosci. 
17: 491-496.

49. Bates D, Mächler M, Bolker B, Walker S (2015): Fitting Linear Mixed-Effects Models Using Ime4. J Stat Software; Vol 1, Issue 1 . Retrieved from https://www.jstatsoft.org/v067/i01.

50. Benjamini Y, Hochberg Y (1995): Controlling the False Discovery Rate: A Practical and Powerful Approach to Multiple Testing. J R Stat Soc Ser B. 57: 289-300.

51. Akbar M, Egli M, Cho Y-E, Song B-J, Noronha A (2018): Medications for alcohol use disorders: An overview. Pharmacol Ther. 185: 64-85.

52. Williams EC, Matson TE, Harris AHS (2019): Strategies to increase implementation of pharmacotherapy for alcohol use disorders: a structured review of care delivery and implementation interventions. Addict Sci Clin Pract. 14: 6.

53. Crabbe JC, Spence SE, Brown LL, Metten P (2011): Alcohol preference drinking in a mouse line selectively bred for high drinking in the dark. Alcohol. 45: 427-440.

54. Mulligan MK, Rhodes JS, Crabbe JC, Mayfield RD, Adron Harris R, Ponomarev I (2011): Molecular Profiles of Drinking Alcohol to Intoxication in C57BL/6J Mice. Alcohol Clin Exp Res. 35: 659-670.

55. Ozburn AR, Falcon E, Mukherjee S, Gillman A, Arey R, Spencer S, McClung CA (2013): The Role of Clock in Ethanol-Related Behaviors.

Neuropsychopharmacology. 38: 2393-2400.

56. Ferguson LB, Ozburn AR, Ponomarev I, Metten P, Reilly M, Crabbe JC, et al. (2018): Genome-Wide Expression Profiles Drive Discovery of Novel Compounds that Reduce Binge Drinking in Mice. Neuropsychopharmacology. 43: 1257-1266. 57. Blednov YA, Black M, Chernis J, Da Costa A, Mayfield J, Harris RA (2017): Ethanol 
Consumption in Mice Lacking CD14, TLR2, TLR4, or MyD88. Alcohol Clin Exp Res. 41: 516-530.

58. Jendryka M, Palchaudhuri M, Ursu D, van der Veen B, Liss B, Kätzel D, et al. (2019): Pharmacokinetic and pharmacodynamic actions of clozapine-N-oxide, clozapine, and compound 21 in DREADD-based chemogenetics in mice. Sci Rep. 9: 4522.

59. Koleti A, Terryn R, Stathias V, Chung C, Cooper DJ, Turner JP, et al. (2018): Data Portal for the Library of Integrated Network-based Cellular Signatures (LINCS) program: integrated access to diverse large-scale cellular perturbation response data. Nucleic Acids Res. 46: D558.

60. UniProt Consortium TU (2008): The universal protein resource (UniProt). Nucleic Acids Res. 36: D190-5.

61. Uys JD, McGuier NS, Gass JT, Griffin WC, Ball LE, Mulholland PJ (2016): Chronic intermittent ethanol exposure and withdrawal leads to adaptations in nucleus accumbens core postsynaptic density proteome and dendritic spines. Addict Biol. 21: $560-574$.

62. DePoy L, Daut R, Brigman JL, MacPherson K, Crowley N, Gunduz-Cinar O, et al. (2013): Chronic alcohol produces neuroadaptations to prime dorsal striatal learning. Proc Natl Acad Sci U S A. 110: 14783-8.

63. Wang J, Cheng Y, Wang X, Roltsch Hellard E, Ma T, Gil H, et al. (2015): Alcohol Elicits Functional and Structural Plasticity Selectively in Dopamine D1 ReceptorExpressing Neurons of the Dorsomedial Striatum. J Neurosci. 35: 11634-11643. 64. Wolstenholme JT, Warner JA, Capparuccini MI, Archer KJ, Shelton KL, Miles MF 
(2011): Genomic analysis of individual differences in ethanol drinking: evidence for non-genetic factors in C57BL/6 mice. (T. Burne, editor) PLoS One. 6: e21100.

65. Sakharkar AJ, Zhang H, Tang L, Shi G, Pandey SC (2012): Histone Deacetylases (HDAC)-Induced Histone Modifications in the Amygdala: A Role in Rapid Tolerance to the Anxiolytic Effects of Ethanol. Alcohol Clin Exp Res. 36: 61-71.

66. Simon-O'Brien E, Alaux-Cantin S, Warnault V, Buttolo R, Naassila M, Vilpoux C (2015): The histone deacetylase inhibitor sodium butyrate decreases excessive ethanol intake in dependent animals. Addict Biol. 20: 676-689.

67. Trazzi S, Fuchs C, Viggiano R, De Franceschi M, Valli E, Jedynak P, et al. (2016): HDAC4: a key factor underlying brain developmental alterations in CDKL5 disorder. Hum Mol Genet. 25: 3887-3907.

68. Cassataro D, Bergfeldt D, Malekian C, Van Snellenberg JX, Thanos PK, Fishell G, Sjulson L (2014): Reverse pharmacogenetic modulation of the nucleus accumbens reduces ethanol consumption in a limited access paradigm.

Neuropsychopharmacology. 39: 283-290.

69. Bourgeron T (2015): From the genetic architecture to synaptic plasticity in autism spectrum disorder. Nat Rev Neurosci. 16: 551-563. 